\title{
SuJEITO E RESISTÊNCIA NA FILOSOFIA DO CONCEITO de Jean Cavaillès
}

\author{
Caio Souto ${ }^{1}$
}

\begin{abstract}
Resumo: A "filosofia do conceito" de Jean Cavaillès, erigida sobre o domínio das matemáticas, costuma ser acusada de eliminar o papel do sujeito da construçấo do conhecimento científico. Em sua defesa, autores como Canguilhem e Badiou evocaram a ação na Resistência Francesa como argumento para a implicação coerente entre sujeito e conhecimento que essa filosofia suscita. Propomos que essa implicação entre sujeito, resistência e pensamento matemático não é arbitrária, mas é uma decorrência necessária da filosofia de Cavaillès.
\end{abstract}

Palavras-chave: Filosofia das matemáticas. Sujeito. Resistência. Cavaillès.

\section{INTRODUÇÁO: A FILOSOFIA DO CONCEITO}

Nas linhas finais do texto póstumo Sobre a lógica e a filosofia da ciência, redigido em 1942, enquanto Jean Cavaillès era mantido preso pelos nazistas por combater pela Resistência Francesa, pelo que ainda seria torturado e morto, dois anos depois, o filósofo-resistente propôs uma divisão entre "filosofia da consciência" e "filosofia do conceito", a qual ficaria famosa por ter antecipado, em vinte anos, as tentativas do que seria, em grande medida, todo o estruturalismo francês:

Não há uma consciência geradora de seus produtos, ou simplesmente imanente a eles, mas ela está cada vez no imediato da ideia, perdida nela e se perdendo com ela e só se ligando com outras consciências (o que seria tentado a chamar de outros momentos da consciência) por elos internos das ideias às quais estas pertencem. $\mathrm{O}$ progresso é material ou entre essências singulares; seu motor, a exigência de ultrapassagem de cada uma

\footnotetext{
${ }^{1}$ Professor de Filosofia pela Universidade do Estado do Amapá (UEAP), Doutor e Mestre em Filosofia pela Universidade Federal de São Carlos (UFSCar). (i) https://orcid.org/0000-0001-5736-2262. E-mail: caiosouto@gmail.com. Macapá, AP, Brasil.
}

http://dx.doi.org/10.1590/0101-3173.2020.v43n4.03.p43 
delas. Não é uma filosofia da consciência, mas uma filosofia do conceito que pode dar uma doutrina da ciência. (CAVAILLÈS, 2008, p. 90, grifo nosso).

Georges Canguilhem retomaria, por sua conta, essa divisão mais de uma vez, dentre as quais mencionaremos duas. Na primeira, em 1967, no auge do estruturalismo, por ocasiấo da inauguração do anfiteatro na Faculdade de Letras de Estrasburgo ${ }^{2}$ que levaria o nome de Jean Cavaillès, ao comentar o legado de seu colega e amigo homenageado, Canguilhem (1996, p. 28-29) retoma o trecho final da passagem que acabamos de citar:

Esse texto [Sobre a lógica e a teoria da ciência] termina com algumas páginas que pareceram a muitos, e primeiro a mim mesmo, por muito tempo enigmáticas. Podemos compreender hoje que o enigma valia por anunciação. Cavaillès atribuiu, vinte anos antes, a tarefa que a filosofia está começando a se reconhecer hoje: substituir o primado da consciência vivida ou refletida pelo primado do conceito, do sistema ou da estrutura. $\mathrm{E}$ acontece que esse filósofo que náo acredita na história, no sentido existencial, refuta de saída, pela açáo que ele desenvolve sentindo-se levado, por sua participação corporal na história e por sua morte histórica, o argumento existencialista dos que procuram hoje desacreditar o que eles chamavam de estruturalismo, condenando-o a gerar, entre outros malfeitos, a passividade diante do fato consumado.

Se, nessa intervenção, Canguilhem invocava o estruturalismo que Sartre tinha acabado de acusar de "imobilismo histórico" (SARTRE, 1966), num outro artigo do mesmo ano, desta vez dedicado ao então recém-publicado As palavras $e$ as coisas, Canguilhem descreve como enxergava, naquele livro de Foucault, a realizaçáo do programa imaginado por Cavaillès e que este último não teria podido realizar, ele mesmo, por conta da interrupçáo brutal de seu pensamento. E o faz quase com as mesmas palavras, acrescentando outras consideraçóes relevantes:

Há vinte anos, as últimas páginas e sobretudo as últimas linhas da obra póstuma de Jean Cavaillès, Sobre a lógica e a teoria da ciência, colocavam a necessidade, para uma teoria da ciência, de substituir a consciência pelo conceito. [...] E há mais. Fuzilado pelos alemães por suas açóes como resistente, Cavaillès, que se dizia spinozista e não acreditava na história em seu sentido existencial, refutou antecipadamente, pela açáo que realizou sentindo-se impelido por sua participação na história tragicamente vivida

\footnotetext{
2 Estrasburgo, capital da Alsácia, após a Ocupação, em 1940, foi anexada pelos nazistas à Alemanha e sua Faculdade de Letras (um dos locais em que tanto Cavaillès quanto Canguilhem lecionaram) foi transferida para Clermont-Ferrand, tendo sido posteriormente realocada em sua cidade de origem, quando a França reassumiu o controle político da região.
} 
até a morte, o argumento daqueles que buscam desacreditar o que chamam de estruturalismo, condenando-o a engendrar, entre outros malfeitos, a passividade diante do fato consumado. (CANGUILHEM, 2012, p. 28).

Michel Foucault, por sua vez, em pelo menos duas ocasióes, voltaria a insistir sobre essa divisão entre duas vertentes rivais no cenário da filosofia francesa: no prefácio à edição inglesa de $O$ normal e o patológico, em 1978 (FOUCAULT, 2001, p. 429-442); e num artigo dedicado a Canguilhem, que é uma segunda versão daquele prefácio, aliás o último texto ao qual daria o seu imprimatur, antes de falecer, em 1984 (FOUCAULT, 2001, p. 1582-1595). Recuperando a divisão de Cavaillès, Foucault a amplia e busca estabelecer uma verdadeira genealogia da "filosofia do conceito" na França. Ao retomar essa clivagem, Foucault não utilizava o termo "filosofia da consciência", a qual Cavaillès empregara em clara referência a Husserl, com quem já havia rompido, como veremos em seguida. Foucault preferirá referir-se, antes, a "uma filosofia da experiência, do sentido e do sujeito", tal como praticada por Sartre e Merleau-Ponty, talvez em consideração à guinada ontológica da fase final da filosofia deste último; do outro lado, Foucault designará uma "filosofia do saber, da racionalidade e do conceito", representada por Bachelard, Cavaillès e Canguilhem, acrescentando o nome de Koyré, na versão de 1984 (FOUCAULT, 2002, p. 430 e p. 1583).

Essa divisão suscitou enorme polêmica, tanto entre os franceses quanto entre os estrangeiros que se dedicaram a identificar as características da epistemologia francesa e sua relação de rivalidade para com a fenomenologia. Neste artigo, não discutiremos tais características, pois já há estudos especializados de enorme valor, podendo nos limitarmos a indicar a compilação de CassouNoguès e Pierre Gillot (2009), o artigo já clássico de Gérard Lebrun (2006), os textos de Jean-François Braunstein $(2002,2009)$ e os de alguns autores da Escola de Stanford, os quais se sentem influenciados pela epistemologia histórica francesa, como Ian Hacking (2009) e Arnold Davidson (2001), que buscaram definir o assim chamado "estilo francês" em epistemologia, além dos conflitos e influências mantidos para com o "estilo analítico" predominante nos países anglófonos. A nosso turno, tentaremos aqui compreender, antes, qual era a posiçáo do sujeito nessa "filosofia do conceito" anunciada por Cavaillès, com o objetivo de verificar como a implicação ético-política de seu pensamento é plenamente coerente à concepção original de sujeito que propóe, e que não estará ausente nas tentativas do assim chamado estruturalismo. 
Para isso, começaremos por analisar brevemente o modo como Alain Badiou, um dos seguidores mais ilustres de Cavaillès, reformula o problema do sujeito, a partir de uma filosofia das matemáticas que lhe é própria, para demonstrar como ela culminará num impasse que um retorno a Cavaillès poderia evitar. Em seguida, demonstraremos como a ausência de uma "filosofia política”, para além de resultar num enigma insolúvel, com relação à atuação política efetiva de Cavaillès, revela, na verdade, uma coerência mais fundamental entre o devir científico e a implicação do sujeito. Por fim, percorrendo alguns aspectos da filosofia de Cavaillès, tentaremos mostrar como esse aparente enigma encontra sua soluçáo num programa que poderia ser o de qualquer filosofia da ciência: uma vez abolido o primado do sujeito, como repensar a implicação entre o conhecimento científico - ou o conhecimento simplesmente - e um sujeito que deverá aparecer como resultado das operaçóes que produzem o conhecimento, o que não significa absolutamente abolir o sujeito.

\section{Alain Badiou e o retorno ao cartesianismo}

Mais ambiciosa do que a divisão estabelecida por Cavaillès, da qual partimos, é a de outro filósofo-matemático, o qual inclusive define a si mesmo como um seguidor de Cavaillès: Alain Badiou. Num texto em que apresenta sua própria versão sobre o pensamento francês, no século XX, de que é ele agora quem vai reivindicar a herança, como filósofo mais novo de uma geração que lhe parecia estar chegando ao fim, Badiou realiza uma reconstituição do que teria sido a filosofia francesa contemporânea, traçando, a seu modo, sua genealogia e identificando o que chamou de suas "operaçóes intelectuais", além de abordar os diálogos com outras formas de conhecimento. Badiou dirá - segundo uma "vocação universal da filosofia, da qual sou um defensor sistemático" (BADIOU, 2015, p. 8) - que toda essa aventura do pensamento francês, durante o século XX, foi um dos momentos do pensamento filosófico universal: "digamos, pois, que vou batizar provisoriamente de 'filosofia francesa contemporânea’ o momento ${ }^{3}$ filosófico na França que, situado essencialmente na segunda metade do século XX, deixa-se comparar, por sua amplitude e por sua novidade, tanto ao momento grego clássico quanto ao momento do idealismo alemão" (BADIOU, 2015, p. 8). E, ao incluir-se nesse momento, a quem caberia - supomos, pelo tom do texto - a tarefa de realizar o seu balanço, deve-se admitir que sua ambição não é pequena.

\footnotetext{
3 Badiou admite que emprestou o termo de Frédéric Worms (2009a), modificando um pouco o seu sentido. Ver também, especificamente sobre a relação entre Cavaillès e Sartre, referentemente a esse momento: Worms (2009b).
} 
Entre as características comuns desse momento, Badiou identifica certos traços, alguns dos quais também são tratados na clivagem de Cavaillès, embora com um objetivo modificado. E, ao retraçar a genealogia de toda essa aventura filosófica, Badiou retroage a Descartes, argumentando que a frequentação pelos franceses à filosofia estrangeira, como a alemã, seria em razão da busca por "uma nova relação entre o conceito e a existência" (BADIOU, 2015, p. 12), com a intenção de "modificar" ou "deslocar" essa relação, cujas raízes francesas remontariam ao cartesianismo. Além disso, também as relaçôes com as ciências, todas as buscas por novas formas de expressão, por novos estilos de escrita, por outras formas de relacionar-se consigo mesmo e, sobretudo, o confronto com a psicanálise, todas essas características da filosofia contemporânea francesa, tudo isso estaria ligado a uma necessidade de reformular o problema do sujeito.

Badiou deslocará, porém, a clivagem de Cavaillès, opondo, não mais a "filosofia do conceito" a uma "filosofia da consciência", mas ao que denominará como uma "filosofia da vida". Isso permitirá que Badiou aproxime, do lado dos "filósofos da vida", nomes como os de Bergson, Sartre, Foucault e Deleuze. E, do outro lado, estarão Brunschvicq, Althusser, Lacan e, especialmente, Cavaillès. Notemos que a estratégia de Badiou funciona bem, se compreendemos que a sua meta é justamente desvincular a filosofia do conceito de uma filosofia da vida, impedindo que houvesse - como queriam Foucault e Canguilhem - uma "filosofia das ciências da vida", a qual fosse oposta a uma "filosofia do sujeito, da experiência ou do vivido". Sabemos da rivalidade de Badiou com Deleuze, por exemplo, que também se servia das matemáticas para pensar a filosofia, mas que compreendia essa relação de um modo muito diferente. É Badiou mesmo quem descreve os pontos principais de sua relaçáo com Deleuze, testemunhando que seu $O$ ser e o acontecimento havia sido uma tentativa de formular uma ontologia do múltiplo diversa daquela tentada por Deleuze, fazendo-o segundo um modelo matemático, e não segundo um modelo vitalista ${ }^{4}$.

\footnotetext{
4 "Percebo pouco a pouco que, ao desenvolver uma ontologia do múltiplo, é em relação a Deleuze que registro minha tentativa, e a mais ninguém. Pois o pensamento do múltiplo opera sob dois paradigmas, há muito apontados por Deleuze: o paradigma 'vital' (ou 'animal') das multiplicidades abertas (na filiação bergsoniana), e o paradigma matematizado dos conjuntos, que pode muito bem ser chamado de estelar, no sentido de Mallarmé" (BADIOU, 2013, p. 11). Mais à frente um pouco, nessa mesma introdução, ao explicar sua motivação para escrever uma resenha elogiosa ao livro - tratava-se de $A$ dobra - de alguém que, por motivos políticos, ele havia criticado com tanta veemência, Badiou diz, demonstrando novamente seu apreço platônico pela eternidade dos conceitos filosóficos: "As sequências da política, sua pressão acontecimental [frappé événementielle], são uma coisa; a eternidade filosófica, ainda que em sua construção esteja sob condição das políticas, é outra” (BADIOU, 2013, p. 12).
} 
Ora, não seria exagero encontrar na clivagem de Badiou uma estratégia para situar a si mesmo como a última tentativa de formulação de uma teoria do sujeito na boa corrente da filosofia do conceito, expelindo para o outro lado as tentativas que não partiriam da formalização matemática. Assim, Cavaillès estará do seu lado, enquanto Canguilhem e Foucault serão deslocados para o outro lado da clivagem. Mais do que isso, contudo, entendemos que a diferença principal entre a reconstituição de Badiou e a de Cavaillès, reivindicada por Canguilhem e Foucault, é diversa. Enquanto Foucault designava a epistemologia histórica francesa como um acontecimento moderno, e mesmo como a legítima herdeira do questionamento crítico moderno aberto pela resposta kantiana ao problema do esclarecimento (FOUCAULT, 2002, p. 431 e p. 1584), Badiou pretende ter havido um momento do universal filosófico, "destinado a instruir a humanidade inteira" (BADIOU, 2015, p. 20). Assim, se Badiou retroage a Descartes, é porque quer resgatar o problema do sujeito em sua universalidade, restituindo o platonismo - como sua filosofia o fará através da formalização matemática da teoria dos conjuntos pós-cantoriana.

Qual poderia ser, pois, a motivação de Badiou em deslocar essa clivagem, criando uma outra divisão, na qual viriam a se opor, às "filosofias do conceito", não as filosofias da consciência ou do sujeito, mas sim o que ele denomina as "filosofias da vida"? Ora, verifica-se justamente que, nessa outra divisão, desaparece o papel da história do âmbito das filosofias do conceito, e agora Badiou pode apresentar-se a si mesmo como o último representante das filosofias do conceito, dando-lhes um significado renovado, em oposição à outra série que parecia ter no rival Deleuze seu último representante. Com efeito, ao abolir a história e o devir do seu papel fundamental, que tanto Brunschvicq quanto Cavaillès reconheceram ao desenvolvimento das matemáticas, Badiou pôde lançar-se à construção de uma nova ontologia.

Tal como Cavaillès, Badiou também pretendeu reverter as filosofias do sujeito e da consciência. Em vez de partir do sujeito transcendental para deduzir a matemática, ele se questiona: "a matemática pura sendo a ciência do ser, como é possível uma teoria do sujeito?” (BADIOU, 1988, p. 12). Para formular tal questão, admitiu como premissa que a matemática, como sistema axiomático desenvolvido segundo a teoria dos conjuntos, é a ontologia: “a apoditicidade dessa disciplina [a matemática] está empenhada [gagée] diretamente no próprio ser que ela pronuncia” (BADIOU, 1988, p. 13). Uma ontologia baseada num conjunto vazio e sem unidade (o "Múltiplo"), permitindo que o real fosse compreendido, na filiaçáo lacaniana, como aquilo 
que impede a formalização unitária absoluta; e sendo o real vazio, a matemática que o pronuncia náo poderia apresentar nenhum objeto.

O interessante dessa filosofia é que ela permite retirar das matemáticas, assim compreendidas como a pronúncia do "ser enquanto ser", o papel de dizerem também os processos contingentes que compóem o mundo. Tais processos estariam, antes, do lado do que Badiou denomina acontecimentos, em oposição ao ser, pois, se o ser é dito pelas matemáticas, de maneira pura e vazia, o acontecimento estará excluído da ontologia, só podendo se dar em quatro "procedimentos genéricos": o amor, a arte, a política e a ciência. Quanto à historicidade intrínseca às ciências, e mesmo às matemáticas, estariam reduzidas ao âmbito dos acontecimentos, portanto, como formas de acesso à verdade, inconfundíveis com a verdade em si mesma.

Porém, a filosofia de Badiou, com certeza uma das mais notáveis e consistentes do pensamento contemporâneo, parece destoar num ponto decisivo daquela de Cavaillès. Cavaillès também considerava que as matemáticas formavam um modelo coerente, embora esse modelo estivesse sujeito a transformaçóes imprevisíveis. Essa redefiniçãa incessante das relaçóes entre os conceitos matemáticos, Cavaillès a reconheceu como sendo resultado de um duplo processo de separação: "longitudinal, ou coextensivo ao encadeamento demonstrativo" (o paradigma); e "vertical, ou instaurando um novo sistema de ligação que utiliza o antigo como base de partida, e não mais estágio atravessado por um movimento, mas objeto de reflexão em seu comportamento atual" (a tematização) (CAVAILLÈS, 2008, p. 41). Esse duplo processo, estando ele em devir, impedia a uniformização das matemáticas numa ontologia finalmente formalizada. Badiou, por fidelidade a um acontecimento - para falar nos seus termos - o da formalizaçáo da teoria dos conjuntos, espera poder destacar tal teoria do devir histórico matemático e, assim, fundar, a partir dela, uma ontologia. Ante isso, contudo, podemos fazer nossa a desconfiança de CassouNoguès, quando questiona: "é possível isolar, de certa maneira, uma teoria dos conjuntos no corpo matemático?” (CASSOU-NOGUĖS, 2006, p. 11); é possível isolar uma ontologia do devir matemático?

\section{O DEVIR MATEMÁTICO}

Antes de decidir-se definitivamente pelo combate que lhe custaria a vida, o último texto que Cavaillès fez publicar, em 1939, abordava um tema sem dúvida comovente, para quem, hoje, já conhece o destino do seu autor. 
Naquela ocasião, Cavaillès escreveu sobre a aposta, tema que, pelo menos desde Pascal, tem direito de cidadania filosófica. Se Cavaillès o abordava por ocasião das teorias recentes sobre as probabilidades, algumas de suas considerações deixam ver que sua reflexão não se limitava a esse domínio, podendo ser interpretadas como substrato teórico ao tema da decisão: "Uma aposta é exata quando se ganha: mas ela deixa, no mesmo momento, de ser uma aposta", sustenta Cavaillès (2012, p. 539).

Logo em seguida, Cavaillès (2012, p. 544-545) acrescenta: "Conhecer o mundo é apostar [...] É a lei de interesses que guia; inserir-se na natureza, vivendo no seio do devir, inventar os movimentos que terão êxito, a própria invenção sendo parte do devir, elemento de um diálogo, como os gestos do corpo na escalada". E, mais à frente, antes de concluir: "A aposta se situa na linha de divisão entre ação pura vivida e especulação autônoma: ao mesmo tempo, ímpeto para o futuro, reconhecimento de uma novidade radical, risco, e, por outro lado, tentativa de dominação por imposição de uma origem, estabelecimento de simetrias" (CAVAILLÈS, 2012, p. 547).

Ora, se apostar é uma exigência - tanto para as ciências quanto para a vida - cujo resultado é necessariamente indeterminado, a decisão que conduz essa atividade, no entanto, só pode ser racional: é preciso escolher, mesmo que não se possa prever as consequências últimas dessa escolha. Nesse pequeno artigo, como observa Hourya Sinaceur, já está em jogo a articulação entre "cálculo e decisão, isto é, matemáticas e ética" (SINACEUR, 2013, p. 45), justamente o ponto para o qual o pensamento e a ação de Cavaillès serão conduzidos, logo em seguida. Uma luta incerta, mas um combate necessário, pois, se o devir matemático decorre de exigências internas, sendo necessário que haja uma experiência cujos resultados são indetermináveis a priori, podendo ocorrer resoluçôes imprevistas ou mesmo a introduçáo de novos conceitos que permitirão uma nova recolocação do problema, também a ação ética deve decorrer de exigências irredutíveis às suas próprias determinaçôes; o contrário da necessidade sendo - não a liberdade, mas, naquele caso - a Colaboração.

É por isso que não faria sentido, para Cavaillès, escrever uma moral. De fato, sua moral ele a demonstraria concretamente, em total convergência com a lógica que ele iria redigir, enquanto estivesse aprisionado em virtude de seu combate. Canguilhem foi muito sensível a essa convergência, e argumentou ser assim já em Spinoza que, contra Descartes, recusava partir do Cogito, 
certamente por achar que a implicação do sujeito na ação pela sua liberdade já deveria estar inscrita na ordem de necessidades de suas próprias causas:

Em suma, essa filosofia [a de Spinoza] que refuta e recusa os fundamentos da filosofia cartesiana, o Cogito, a liberdade em Deus e no homem, essa filosofia sem sujeito, muitas vezes assimilada a um sistema materialista, essa filosofia vivida pelo filósofo que a pensou, imprimiu no seu autor a força necessária para se insurgir contra o fato consumado. A filosofia deve dar conta de tal força. (CANGUILHEM, 2006, p. 207-208).

Insurgência "contra o fato consumado": são essas mesmas palavras que Canguilhem utilizava, nas muitas homenagens que prestou a Cavaillès, retomadas ainda em referência a Foucault. Badiou compreendeu isso bem, rendendo também seus tributos aos seus precursores resistentes. No prefácio a uma obra na qual afirma, a respeito da política, sua exterioridade com relação a qualquer teoria, o que interditaria a possibilidade de uma "filosofia política", Badiou (1998) não hesitou em fazer excluir do domínio da sociologia - ou da história sociológica - a explicação dos acontecimentos da Resistência, e mesmo de qualquer acontecimento:

O "por lógica" de Canguilhem deve se entender como um duplo desvio [écart]. Ele se desvia de um "por necessidade social" que dissolveria a escolha em representaçóes coletivas apreensíveis pela sociologia histórica. Ele se desvia de um puro imperativo moral que dissolveria a escolha em disposiçōes doutrinais exteriores à situação concernida. De fato, a escolha não tem sua inteligibilidade nem no coletivo objetivo nem numa subjetividade de opiniấo. Ela tem sua inteligibilidade em si mesma, no processo sequencial da ação, assim como um axioma só é inteligível pelos desdobramentos da teoria que ele sustenta. (BADIOU, 1996, p. 15).

Outro ponto de coerência importante entre a lógica da "experiência matemática" de Cavaillès e o que chamaremos sua "experiência ética" como resistente é que ambas as "experiências", irredutíveis entre si, pois são encadeadas necessariamente em domínios eles mesmos irredutíveis como são os do desenvolvimento das matemáticas e o dos acontecimentos políticos, representam uma ruptura para com um estado atualmente dado. Quando um problema matemático é solucionado ou tem os seus termos modificados

\footnotetext{
${ }^{5}$ Nas indagaçóes incompletas do Tratado da emenda do intelecto, Spinoza postulava algo como uma decisão que conduzisse o pensamento a lançar-se às redes causais de ordem necessárias, porém, a anterioridade dessa decisão na ordem do pensamento não tem valor ontológico, pois, se a substância compreende o pensamento, decidir por aceder a ela é uma necessidade.
} 
pela introdução de novos conceitos e isso acarreta a sua solução, observase um progresso, isto é, uma mudança efetiva de ordem qualitativa (e será assim também com os demais autores vinculados à epistemologia histórica francesa, em seus respectivos domínios: Bachelard, Koyré, Canguilhem). Correlatamente, um ato de resistência implica de imediato uma ação concreta na realidade, que arrisca modificá-la ou pode sucumbir a ela, mas nunca se the submeter. Badiou conclui, assinalando que, sendo a Resistência uma escolha racional, a decisão pelo seu contrário, isto é, naquele contexto, pela Colaboração, só poderia advir de uma ausência de pensamento, assim como em Spinoza aquele que náo lutava por sua liberdade só podia estar privado de pensamento, ficando à mercê de determinaçóes exteriores, uma vez que o pensamento o conduziria necessariamente à luta pela sua libertação (náo sendo, portanto, a necessidade um fatalismo, mas uma imprevisibilidade cujo efeito é necessário, ou uma necessidade cujo efeito é imprevisível).

De todos os textos de Cavaillès, sem dúvida, o último que escreveu, em 1942, foi o que recebeu merecidamente maior atenção, não apenas pelas condiçôes heroicas sob as quais foi concebido (longe dos livros, na solidão da prisão), mas sobretudo por ter anunciado o programa de uma filosofia do conceito. Esse texto, que ficou conhecido com o título que Canguilhem e Ehresmann lhe deram - Sobre a lógica e a teoria da ciência - objetiva superar o papel da consciência na fundação da racionalidade. As duas teses de doutoramento de Cavaillès - Método axiomático e formalismo e Observaçóes sobre a formação da teoria abstrata dos conjuntos - ambas defendidas em 1937, sob a orientação de Brunschvicq, publicadas no ano seguinte, dedicaram-se respectivamente ao problema da crise da fundamentação das matemáticas (Grundlagenkrise) ${ }^{6}$ e à reconstrução histórica da teoria dos conjuntos, até o estado evolutivo em que se encontrava à época. $\mathrm{Na}$ tese complementar,

\footnotetext{
${ }^{6}$ A teoria dos conjuntos tem, segundo Cavaillès, sua pré-história na tentativa logicista de Bolzano de criar uma sintaxe universal que dava prosseguimento ao projeto idealizado por Leibniz, e que foi sucedida, em suas intençôes, por Boole e sobretudo pelo programa de Hilbert, onde se poderia encontrar uma razão matemática suficiente a todo o seu desenvolvimento (uma "metamatemática"). Dedekind, em seguida, revelaria algumas dificuldades de tais tentativas, e foi procurado por Cantor, iniciando uma troca de correspondências - que Cavaillès traduziu e publicou, com o acréscimo de uma introdução - na qual é possível observar a historicidade do desenvolvimento de um problema matemático, resultando na formulação, enfim, pelo próprio Cantor, da teoria dos conjuntos. A crise, de que fala Cavaillès, instaurada por essa teoria, se instaurou na medida em que ela obstava uma fundamentação das matemáticas, assim como os projetos logicistas posteriores, como os de Frege, ou os de Carnap e do Círculo de Viena. Tal era a principal motivaçáo de Cavaillès, que assim iniciava sua tese principal: "O problema do fundamento da matemática só ganhou toda a sua importância com a crise da teoria dos conjuntos” (CAVAILLÈS, 2012, p. 13).
} 
poderíamos dizer que se pratica algo como uma epistemologia histórica dos conceitos matemáticos concernindo à formação da teoria dos conjuntos.

Se, nas suas duas teses de doutoramento, Cavaillès se propunha debater os problemas concernentes à teoria dos conjuntos e da fundamentação das matemáticas, em Sobre a lógica e a teoria da ciência, seu objetivo se expande para além desse âmbito e abarca outras consequências para além do domínio matemático. Seu alvo principal nesse texto é o que ele chama as "filosofias da consciência”, representadas por Kant - no início do texto - e por Husserl - em toda a terceira e última parte, também a maior e mais densa - até concluir com a célebre frase na qual frisa que "não é uma filosofia da consciência, mas uma filosofia do conceito que pode dar uma doutrina da ciência” (CAVAILLÈS, 2008, p. 90). Na parte intermediária do texto, Cavaillès discute uma série de autores que teriam tentado fundamentar as matemáticas pela lógica, introduzindo-os progressivamente: Bolzano, Frege, Russell, o Wittgenstein do Tractatus, Tarski e Carnap, considerando-os todos como "logicistas", isto é, como propondo uma fundamentação de todo o conhecimento pela lógica.

A importância inicial de Kant estaria em ter reconhecido o caráter necessário e normativo de regras lógicas na formação do conhecimento. Mas, para Cavaillès, ao submetê-las a uma faculdade, a do entendimento, Kant teria recaído numa dificuldade: como categorias "puras" poderiam estar submetidas a uma faculdade do sujeito? E, a fim de resolvê-la Kant, teria apelado à consciência, a qual garantiria no nível transcendental a dedução de tais categorias. Ao fazê-lo, Kant estabelecia uma divisão estanque entre sensibilidade e entendimento, intuição e conceitos, preservando a unidade sistêmica às formas lógicas. E de onde mais Kant poderia emprestar tais categorias lógicas, uma vez que havia rompido o laço entre elas e qualquer devir intrínseco - já que seriam juízos sintéticos a priori - senão de uma lógica pré-existente em sua facticidade histórica (como aquela formalizada pela Lógica de Port Royal)?

\footnotetext{
7 Tal crítica de Cavaillès a Kant encontraria eco em Foucault, n’As palavras e as coisas, quando se tratará de mostrar como Kant é apenas a expressão filosófica de um problema característico da episteme moderna, aquele da disjunção, no interior do signo, entre significante e significado. Não estamos dizendo que a função exercida por Kant, nessa obra de Foucault, seja a de preservar as categorias lógicas historicamente fundadas no a priori epistêmico da Idade Clássica. Pelo contrário, a cisão interna ao signo, provocada pela episteme moderna, abriu à linguagem a historicidade própria das línguas e da linguagem. É essa historicidade intrínseca aos conceitos que Cavaillès está buscando, com a diferença de que ele a busca no âmbito específico do conhecimento científico, enquanto a arqueologia foucaultiana buscará o seu a priori para além do desenvolvimento específico da ciência, na própria episteme moderna.
} 
Assim, por mais que Kant tivesse encontrado nas matemáticas o melhor exemplo da razão pura estendendo-se a si mesma, Cavaillès dirá que ele arrancou o seu desenvolvimento à progressáo efetiva de uma experiência matemática. Conforme Cavaillès, se as matemáticas carecem de uma experiência externa (como a de uma intuiçáo, em sentido kantiano) para se desenvolver, tal desenvolvimento só ocorreria, no entanto, em virtude de uma experiência que, não sendo uma experiência sensível, é propriamente matemática. Como exemplifica Hourya Sinaceur (2013, p. 78): "calcular, figurar, traçar funçóes, desenhar diagramas, inventar conceitos, jogar com o infinito, caracterizar numericamente o contínuo, etc., todas operaçóes que não são unificação do sensível”.

Quanto à exigência de uma base ontológica desvencilhada de uma consciência, Cavaillès a encontra uma primeira vez formulada em Bolzano, cuja importância como pré-história da teoria dos conjuntos já havia sido reconhecida em inúmeras passagens de Método axiomático e formalismo. Agora, Bolzano é invocado por ser aquele que teria autonomizado o movimento constitutivo da arquitetura própria das construçóes científicas, cujo motor seria a demonstração de uma consciência subjetiva:

Pela primeira vez, talvez, a ciência não é mais considerada como simples intermediária entre o espírito humano e o ser em si, dependendo tanto de um quanto do outro e náo tendo realidade própria, mas como um objeto sui generis, original em sua essência, autônomo em seu movimento (CAVAILLÈS, 2008, p. 36).

Não há mais signo, nem necessidade de qualquer esquematismo que viesse garantir a aplicação de conceitos do entendimento a objetos da experiência, pois uma fórmula ou um diagrama matemático já são, eles mesmos, situaçôes reais e efetivas, fruto de uma experiência ocorrida no nível autônomo das matemáticas. Contrariamente a Kant, o conhecimento puro não seria vazio, pois seria preenchido de atos que possuem densidade histórica, mesmo que se trate de uma história intrínseca ao desenvolvimento matemático.

Porém, ainda aqui persiste uma dificuldade, também presente em Kant, porque, se, para este último, as formas lógicas, por terem perdido o laço com os objetos, permaneciam estanques, para Bolzano também não haveria uma contrapartida dinâmica que explicasse o devir efetivo dos conceitos matemáticos, segundo observa novamente Hourya Sinaceur (2013, p. 72-73): 
Do ponto de vista intrínseco, que separa as matemáticas de suas aplicações, os conteúdos se autoengendram uns a partir dos outros num ritmo necessário e imprevisível. O sentido se autoconstitui numa transformação perpétua de suas concreçóes particulares.

E essa dificuldade também não será devidamente enfrentada pelos demais autores confrontados por Cavaillès, antes de invocar Husserl. Ele analisa Frege e Russell, os quais teriam examinado as propriedades sintáticas das línguas formais, e sobretudo Carnap, que, dando sequência a essa tradição, procurou reduzir toda a filosofia a uma única sintaxe lógica unificada como teoria geral da ciência. Cavaillès dirá que as necessidades próprias aos problemas matemáticos, cujas resoluçôes seriam imprevisíveis, poderiam exigir uma pluralidade de línguas e de sintaxes, todas elas irredutíveis a uma única e mesma lógica. Tais autores teriam, assim, estagnado o processo inerente ao desenvolvimento matemático.

A propósito, assinala outro comentador, desta vez Jan Sebestik: "O que ele [Cavailllès] reprova a Carnap é o desconhecimento da temporalidade própria à ciência, lugar da necessidade, pois a progressão se faz pela via demonstrativa, e do imprevisível, pois ela só se realiza por rompimentos [éclatements] e uma reorganização completa das matemáticas" (SEBESTIK, 2008, p. 122). Por fim, ainda, Cavaillès replicará que, na passagem para as ciências físicas, que o Círculo de Viena tentava fundamentar pela mesma sintaxe lógica, haveria exigências adicionais às das matemáticas:

O processo experimental verdadeiro está em outra parte, nas visadas [visées], nas utilizaçóes e construções efetivas de instrumentos, todo o sistema cósmico-técnico onde seu sentido se revela e cuja unidade, tanto quanto a relação com o desenrolar matemático autônomo, colocam o problema fundamental da epistemologia física" (CAVAILLÈS, 2008, p. 55).

E, não podendo encontrar, em nenhum desses autores, as respostas a tais exigências, Cavaillès foi ao encontro daquele filósofo que, para ele, parecia estar mais próximo de resolvê-las: Husserl. 


\section{O ROMPIMENTO COM A FENOMENOLOGIA}

A ciência se move fora do tempo.

Jean Cavaillès (2008, p. 37)

Cavaillès foi um dos que escutaram presencialmente as conferências de Husserl na Sorbonne, em 1929, depois publicadas com o título Meditaçóes cartesianas, indo visitá-lo pessoalmente em 1931, quando em temporada de estudos na Alemanha. Inicialmente muito entusiasmado com as promessas que a fenomenologia propunha para a lógica e para a teoria das ciências, ao estudá-la mais a fundo, Cavaillès notou que suas soluçôes não eram satisfatórias. Tomando as teses tardias de Husserl desenvolvidas em Lógica formal e transcendental (1929) e na Krisis (1936), Cavaillès reteve que sua filosofia transcendental reintroduzia a consciência, mediante o conceito de intencionalidade, na fundamentaçáo das matemáticas. A perspicácia de Husserl, que superava a dualidade kantiana entre sujeito e objeto, salvaguardando a efetividade ao processo racional de que decorrem as matemáticas, estava em evitar, a um só tempo, sacrificar a autonomia da estrutura do objeto e relegar a lógica a um absoluto formal alheio ao mundo, postulando uma "equivalência de conteúdo entre apofântica e ontologia formal" (CAVAILLÈS, 2008, p. 64) ${ }^{8}$. Da lógica à matemática e, por conseguinte, à física, a intencionalidade (correlação entre atividade e sentido matemáticos) permitiria que houvesse um movimento coerente: "a autoridade da lógica sobre a física se acha dessa forma explicada. Com efeito, é um só e único movimento que, por meio da matemática, se desenvolve até as realidades do mundo" (CAVAILLÈS, 2008, p. 66).

Nesse ponto, Husserl deixava a lógica simplesmente formal para estabelecer uma lógica transcendental, concebendo esta como uma síntese última entre lógica e consciência, o que possibilitaria restabelecer a efetividade da lógica que Kant havia impossibilitado, na medida em que a apartava do objeto sensível. Perguntando-se pela origem da produção de sentido na consciência, Husserl pôde fazer conduzir os conteúdos formais da lógica à constituição transcendental desses conteúdos, onde encontrava a consciência tética como fonte e fundamento: "uma terra que não se move". Ora, sendo a consciência direcionada intencionalmente para o objeto, ao direcionar-se para si mesma, dizia Husserl, ela tomaria consciência de si e de suas funçôes transcendentais.

\footnotetext{
${ }^{8}$ Comentando essa passagem, Sinaceur enfatiza: "A tese de Husserl é a correspondência, a 'solidariedade efetiva', entre apofântica formal e ontologia formal, todo objeto ou relação formal entre objetos sendo expressa por um juízo" (SINACEUR, 2013, p. 116).
} 
Mas é aqui que Cavaillès reconhece um dilema ainda maior: "Se a lógica transcendental fundamenta verdadeiramente a lógica, não há lógica absoluta (isto é, regendo a atividade subjetiva absoluta). Se há uma lógica absoluta, ela não pode tirar sua autoridade senão de si mesma, ela não é transcendental" (CAVAILLÈS, 2008, p. 78) ${ }^{9}$. E tais termos - absoluto e fundador - que dizem respeito à filosofia de Husserl, serão então abandonados por Cavaillès, ao propor sua própria filosofia, cujo programa ele lança em poucas frases conclusivas, nomeando-a como "a filosofia do conceito". Ao contrário do projeto fundacionista da fenomenologia, Cavaillès sugere que o conhecimento científico se desenvolve segundo verdades inerentes a respectivos modelos, necessariamente múltiplos, multiplicidades essas que também recusariam a condição absoluta de uma filosofia transcendental. E Cavaillès acompanhou o pensamento de Husserl nas refutaçóes aos demais pensadores que o trouxeram até esse ponto, para depois romper com ele e defender uma filosofia que valorizasse a autonomia da prática matemática em seu devir, negando toda tentativa de restituição de uma intuição originária ${ }^{10}$.

Diferentemente também das lógicas estritas, a de Cavaillès não concebe uma base lógica única a todo pensamento científico. A relação das matemáticas entre si e delas com as ciências da natureza residiria, antes, num entrecruzamento de experiências científicas distintas, numa coordenaçáo que não pode ser estabelecida a priori. Além disso, nas relaçóes entre modelos matemáticos, realidade física e tempo histórico, poderiam entrecruzar-se infinitas cadeias de necessidades, numa grande rede de afecçôes só possíveis de serem aferidas

\footnotetext{
9 Quanto a isso, Derrida, em estudo sobre a Krisis, dirá algo parecido a respeito da aporia entre empírico e transcendental na origem da geometria, acusando-lhe uma confusão entre um empirismo e uma metafísica: "Se a possibilidade das objetividades ideais é, ao mesmo tempo, a priori e empírica, por que é apenas num certo momento objetivo que as idealidades aparecem em sua rigorosa exatidáo? Por que e como esse rigor ou essa exatidão são engendrados a partir de uma inexatidão? Uma vez mais, pergunta-se qual experiência pode conciliar a temporalidade contínua com a produção ou a intuição de um a priori absoluto. Uma vez mais, a descrição de Husserl trai seus princípios [...] Com efeito, fracassando em apreender o sentido concreto a priori da gênese tecnológica, Husserl deve invocar uma razão escondida na história que desvelará toda reativaçáo da gênese. Mas enquanto tal e em sua pureza, essa razão que se encontra em toda origem genética não é, ela mesma, engendrada. Nessa perspectiva, que se deve aqui qualificar, do próprio ponto de vista de Husserl, de metafísica e formal, a gênese não é mais que uma estratificação de sedimentos factícios dissimulando o sentido originário da história" (DERRIDA, 1990, p. 270).

${ }^{10}$ Outro ex-aluno de Cavaillès, que dá, a seu modo, prosseguimento à epistemologia histórica no âmbito das matemáticas, Gilles-Gaston Granger ressalta: "Nessa acepção, não há a priori propriamente dito: mesmo a lógica, consistindo em verificar um procedimento, é uma experiência. A intuição, na medida em que é uma maneira de levar em conta os objetos matemáticos, está em constante progresso e constrói seus sucessivos momentos e níveis pari passu com a necessária criaçáo de novos conceitos" (GRANGER, 2003, p. 296).
} 
em ato, nunca em potência. Abandonando o campo transcendental, Cavaillès integrará a dimensão do devir na teoria da razão, de múltiplas historicidades correspondendo a múltiplos modelos de racionalidade que se afetam, mas não se unificam. E só uma dialética ${ }^{11}$ é que poderia dar conta da geração das necessidades matemáticas, todavia, deixando a consciência excluída do seu ponto de partida, o que não significa que Cavaillès a destituísse absolutamente de sua filosofia. Ao contrário, e aqui é novamente Spinoza - e não Hegel, de quem ele desconfiava - que o inspira, o sujeito deveria aparecer como implicado nos encadeamentos inteligíveis dos modelos matemáticos, estando também sempre em transformação a realidade desses processos nos quais o sujeito se constituiria ${ }^{12}$.

Muitos foram os filósofos da ciência, na França, que se sentiram influenciados pelo programa da "filosofia do conceito" que concilia de modo original racionalidade e história. Vê-se que ele não era propriamente novo e que, antes de Cavaillès, Bachelard (desde o final da década de 1920) já praticava algo similar para as ciências da matéria e, antes dele, já Comte havia dito só ser possível conhecer uma ciência se conhecêssemos a sua história. E quanto a essa "história", a filosofia do conceito, a qual não pudemos conhecer em todos os seus desdobramentos pela interrupção prematura da vida de seu criador, postulava para si um devir autônomo, o que significa dizer, em seus próprios termos, que esse devir se daria fora do tempo.

\section{CONSIDERAÇÓES FINAIS: A RESISTÊNCIA POR LÓGICA}

Jean Cavaillès é a lógica da resistência vivida até a morte. Georges Canguilhem (1996, p. 35)

Numa outra intervenção de Badiou a respeito de Cavaillès, desta vez invocando sua ação na Resistência na introdução do seu Compêndio de metapolítica (BADIOU, 1998, p. 9-17), que retoma, por sua vez, uma

\footnotetext{
11 "A necessidade geradora não é a de uma atividade, mas de uma dialética" (CAVAILLÈS, 2008, p. 90).

${ }^{12}$ A afirmação de Cassou-Noguès é precisa: "Na realidade, Cavaillès opera uma inversão com relação às filosofias da consciência e, em vez de explicar os objetos da ciência a partir da consciência, tenta explicar a consciência a partir do movimento da ciência. O problema é duplo. Com efeito, recusar a primazia da consciência é, por um lado, recusar a posiçấo de uma consciência constituinte, mas, por outro lado, é desistir de considerar a consciência como um dado primitivo. Deve-se, portanto, constituir e, antes disso, definir a consciência a partir do devir autônomo das matemáticas" (CASSOUNOGUÈS, 2001, p. 2).
} 
homenagem feita conjuntamente a Canguilhem e Cavaillès (BADIOU, 2009, p. 5-13), Badiou comenta um pequeno livro de Canguilhem, pouco lembrado, aliás, nas análises do conjunto de sua obra, o opúsculo Vida e morte de Jean Cavaillès. É nele que Canguilhem apresenta, se não uma teoria do sujeito, ao menos a resolução daquilo que ele mesmo reconhecia como um enigma, o qual nos vem motivando até aqui: qual relação de necessidade poderia existir entre uma filosofia do conceito e a implicação do sujeito? E qual relação se poderia estabelecer, nessa filosofia, entre lógica e moral? ${ }^{13}$

Enquanto filósofo, Cavaillès buscou dar às matemáticas uma autonomia completa ante os demais saberes, demonstrando que o seu desenvolvimento deveria ser considerado unicamente a partir das resoluçóes internas dos problemas que lhes concerniriam. Desde suas duas teses, Cavaillès já expunha seu conceito de "experiência matemática", que nada deve ao empirismo. "Por experiência", dizia ele, "entendo um sistema de gestos, regido por uma regra e submetido a condiçóes independentes desses gestos" (CAVAILLÈS, 2012, p. 495). Desses gestos, cujas regras lhes são independentes, emergiria um sujeito, isto é, uma atividade de resolução contínua dos problemas matemáticos engendrados interna e autonomamente:

[...] há uma objetividade, baseada matematicamente, do devir matemático; é a exigência de um problema que obriga a despojar um método de acidentes que nenhuma reflexão percebia como inúteis, é o vigor interno de um método [...]" (CAVAILLĖS, 2012, p. 185).

Tal experiência matemática se daria em favor do desenvolvimento das ideias matemáticas, segundo o encadeamento de seus elos efetivos.

Canguilhem utilizava o exemplo dado por Cavaillès, que respondeu com sua vida e com sua morte ${ }^{14}$ às exigências ético-políticas de uma filosofia do conceito, numa espécie de resposta antecipada às objeçóes do existencialismo. Após citar uma fala em que Cavaillès se confessava spinozista e se dizia cercado de necessidades, sendo da mesma natureza as necessidades

\footnotetext{
${ }^{13}$ Esse assunto, aliás, já ocuparia Canguilhem desde cedo. Basta ver alguns dos temas dos cursos que proferiu, durante a década de 1930, além de ter publicado, em coautoria com Camille Planet, um Tratado de lógica e moral, em 1939 (CANGUILHEM, 2011, p. 633-923).

${ }^{14}$ Para um relato sobre as açôes praticadas por Jean Cavaillès, durante a Resistência, ver Ferrières (1982). Para as ações de Canguilhem, o qual exerceu a função de médico na Resistência, um dos únicos momentos de sua vida, aliás, em que exerceu essa profissão, ver Roudinesco (2010, p. 1-32).
} 
lógicas dos encadeamentos matemáticos e a necessária resistência ao nazismo, Canguilhem descrevia assim a ação do amigo:

Geralmente, para um filósofo, engajar-se em escrever uma moral é preparar-se para morrer em seu leito. Mas Cavaillès, no momento mesmo que fazia tudo o que se pode fazer quando se quer morrer no combate, compunha uma lógica. Ele mostrou assim sua moral, sem ter de escrevêla. [...] Cavaillès, filósofo combatente, ensina aos homens ditos de ação que a ação não é uma inconsistente e covarde prática empírica. Cavaillès, filósofo matemático, nutrido pela poesia, que citava Rimbaud em suas aulas sobre a experiência, que dizia ter-se achado no mundo do Bateau ivre, contemplando pela primeira vez o porto de Estrasburgo, ensina aos terroristas literários que, antes de ser a irmá do sonho, a açáo deve ser a filha do rigor. (CANGUILHEM, 1996, p. 29-30).

Noutro texto, Canguilhem prosseguirá pela dedução lógica da ação prática de Cavaillès, invocando a liberdade necessária, em sentido spinozista, daquele que age conforme a uma exigência, afirmando que Cavaillès foi "Resistente por lógica":

O nazismo era inaceitável, na medida em que era a negação, mais selvagem do que sábia, da universalidade, na medida em que anunciava e procurava o fim da filosofia racional. A luta contra o inaceitável era, então, inevitável. E por luta não se deve entender a indignação cochichada nos corredores, o porta a porta patriótico, a alimentação das caixas de correio com panfletos vingativos. Por luta, deve-se entender o combate com as mãos armadas. E por armas, todas as armas. Eis, pois, aí um intelectual que, sem pressão de situação pessoal, por escolha totalmente livre, faz-se chefe de rede, primeiro e sempre pagando com sua pessoa, chefe de agentes de informaçóes, de colocadores de explosivos, de sabotadores. Um chefe executor, um filósofo terrorista: eis aí Cavaillès. [...] A lógica é implacável. [...] Sua filosofia matemática náo foi construída em referência a algum sujeito suscetível de ser momentânea e precariamente identificado com Jean Cavaillès. Essa filosofia da qual Jean Cavaillès está radicalmente ausente comandou uma forma de açâo que o conduziu, pelos estreitos caminhos da lógica, até essa passagem de onde não se volta. (CANGUILHEM 1996, p. 34-35).

Canguilhem apresenta razões para afirmar que a ação militar de Cavaillès era uma necessidade que não decorria nem de um imperativo moral, nem de uma contingência existencial. Uma necessidade compreendida no sentido que a filosofia matemática de Cavaillès - que reiteramos dizer-se spinozista - a compreendia: uma decisão livre para agir, resistindo a uma coação 
externa mais forte e que coibiria toda liberdade. A decisão contrária, para ele, corresponderia à submissão. Não sendo regida nem por uma finalidade, nem pelo puro acaso, sua decisão pela Resistência era um gesto ético livre, na busca pela sua emancipação das "impurezas do movimento histórico" ${ }^{15}$. Exercício da mais absoluta coerência de um pensamento que procurou as relaçóes de afecção entre sujeito e conhecimento, não num a priori transcendental, mas no irredutível de suas experiências respectivas.

SOUTO, C. Subject and resistance in Jean Cavailllès' philosophy of concept. Trans/form/ação, Marília, v. 43, n. 4, p. 43-64, Out./Dez., 2020.

\begin{abstract}
Jean Cavaillès's "philosophy of concept", built on the domain of mathematics, is often accused of eliminating the role of the subject from the construction of scientific knowledge. In their defense, authors like Canguilhem and Badiou evoked the action in the French Resistance as an argument for the coherent implication between subject and knowledge that this philosophy evokes. We propose that this implication between subject, resistance and mathematical thinking is not arbitrary, but is a necessary consequence of the Cavaillès's philosophy.
\end{abstract}

Keywords: Philosophy of mathematics. Subject. Resistence. Cavaillès.

\title{
REFERÊNCIAS
}

ARON, Raymond. Prefácio. In: CAVAILLÈS, Jean. Obras completas de filosofia das ciências. Tradução Abner Chiquieri. Rio de Janeiro: Forense Universitária, 2012, p. 173176.

BADIOU, Alain. L'être et l'événement. Paris: Seul, 1988.

BADIOU, Alain. Abrégé de métapolitique. Paris: Seuil, 1998.

BADIOU, Alain. Georges Canguilhem and Jean Cavaillès". In: BADIOU, Alain. Pocket Panthéon: figures of postwar philosophy. Tradução inglesa David Macey, London / New York: Verso, 2009, p. 5-13.

BADIOU, Alain. La clameur de 1'Être. Paris: Fayard, 2013.

BADIOU, Alain. A Aventura da filosofia francesa contemporânea. Tradução Antônio Teixeira. Belo Horizonte: Autêntica, 2015.

${ }^{15}$ Palavras de Raymond Aron, o qual também se pronunciou sobre o gesto de decisão de Cavaillès (ARON, 2012, p. 175). 
BRAUNSTEIN, Jean-François. Bachelard, Canguilhem, Foucault: le 'style français' en épistémologie. In: WAGNER, Pierre (éd.). Les Philosophes et la Science. Paris: Gallimard, 2002, p. 920-963.

BRAUNSTEIN, Jean-François. Fleck, Canguilhem, Foucault. Ludwig Fleck et le "style français" en philosophie des sciences. In: LÖWY, I. e JAS, N. (éd.). Genèse et développement d'un fait scientifique (1935). Retour sur les fondements, la fécondité et l'actualité de la pensée de Ludwik Fleck. Zurich: Collegium Helveticum, 2009, p. 63-80.

CANGUILHEM, Georges. Vie et mort de Jean Cavaillès. 3a ed. Paris: Allia, 1996.

CANGUILHEM, Georges. O cérebro e o pensamento. Natureza Humana 8(1): 183210, jan.-jun. 2006, p. 183-210.

CANGUILHEM, Georges. Oeuvres completes: tome I. Écrits philosophiques et politiques (1926-1939). Paris: Vrin, 2011.

CANGUILHEM, Georges. Michel Foucault: morte do homem ou esgotamento do Cogito? Tradução Fabio Ferreira de Almeida. Goiânia: Ricochete, 2012.

CASSOU-NOGUÈS, Pierre. Conscience et réflexivité dans la philosophie mathématique de Cavaillès. Methodos: savoirs et textes, 1/2001, p. 1-14. [disponível em http:// journals.openedition.org/methodos/55; acesso em 01/03/2018]

CASSOU-NOGUÈS, Pierre. L'excès de l'état par rapport à la situation dans L'être et l'événement de A. Badiou. Methodos: savoirs et textes, 6/ 2006, p. 1-13. [disponível em http://journals.openedition.org/methodos/548; acesso em 01/03/2018]

CASSOU-NOGUĖS, Pierre; GILLOT, Pierre. Le concept, le sujet et la science: Cavaillès, Canguilhem, Foucault. Paris: Vrin, 2009.

CAVAILLÈS, Jean. Sur la logique et la théorie de la science. 2a ed. Paris: Vrin, 2008.

CAVAILLÈS, Jean. Obras completas de filosofia das ciências. Tradução Abner Chiquieri. Rio de Janeiro: Forense Universitária, 2012.

DAVIDSON, Arnold. The emergency of sexuality: historical epistemology and the formation of concepts. Harvard: Harvard University Press, 2001.

DERRIDA, Jacques. Le problème de la genèse de la géometrie de Husserl. Paris: Seuil, 1990.

FERRIÈRES, Gabrielle. Jean Cavaillès: un philosophe dans la guerre, 1903-1944. Paris: Seuil, 1982.

FOUCAULT, Michel. Dits et écrits II. 1976-1988. 2a ed. Paris: Gallimard, 2002.

GRANGER, Gilles-Gaston. Cavaillès et Lautman, deux pionniers. Revue philosophique de la France et de l'étranger, 2002/3, Tome 127, p. 293-301 [disponível em https:// www.cairn.info/revue-philosophique-2002-3-page-293.htm; acesso em 01/03/2018]. 
HACKING, Ian. Ontologia história. Tradução Leila Mendes. São Leopoldo: Unisinos, 2009.

HUSSERL, Edmund. Lógica formal y lógica transcendental: ensayo de una crítica de la razón lógica. Traducción Luís Villoro. Ciudad de México: CEF, 1962.

\section{HUSSERL, Edmund. A crise das ciências europeias e a fenomenologia} transcendental. Rio de Janeiro: Forense Universitária, 2012.

LEBRUN, Gérard. A ideia de epistemologia. In: LEBRUN, Gérard. A filosofia e sua história. Trad. Carlos Alberto Ribeiro de Moura. São Paulo: Cosac Naify, 2006, pp. 129-144. ROUDINESCO, Elisabeth. Philosophy in turbulent times: Canguilhem, Sartre, Foucault, Althusser, Deleuze, Derrida. Tradução para o inglês William McCuaig. New York: Columbia University Press, 2010.

SARTRE, Jean-Paul. Jean-Paul Sartre répond. In: Revue L'Arc, n 30. Paris, 1966, p. 87-96.

SEBESTIK, Jan. Postface. In: CAVAILLÈS, Jean. Sur la logique et la théorie de la science, 2a ed. Paris: Vrin, 2008, p. 91-142.

SINACEUR, Hourya Benis. Cavaillès. Paris: Les Belles Lettres, 2013.

WORMS, Frédéric. Moments : la philosophie en France au XXe siècle. Paris, Gallimard, 2009a.

WORMS, Frédéric. Sartre et Cavaillès: nécessité et existence dans le moment philosophique de la Seconde guerre mondiale. In: CASSOU-NOGUÈS, Pierre; GILLOT, Pierre. Le concept, le sujet et la science: Cavaillès, Canguilhem, Foucault. Paris: Vrin, 2009b, p. 59-74.

Recebido: 26/6/2018

Aceito: 29/04/2020 
SOUTO, C. 